\title{
Ryszard Kapuściński et Andrzej Stasiuk, deux écrivains polonais à fronts renversés?
}

\section{Anne-Marie Monluçon}

\section{OpenEdition}

\section{Journals}

Édition électronique

URL : http://journals.openedition.org/recherchestravaux/526

DOI : 10.4000/recherchestravaux.526

ISSN : 1969-6434

Éditeur

UGA Éditions/Université Grenoble Alpes

\section{Édition imprimée}

Date de publication : 15 mai 2012

Pagination : 141-171

ISBN : 978-2-84310-227-1

ISSN : 0151-1874

\section{Référence électronique}

Anne-Marie Monluçon, « Ryszard Kapuściński et Andrzej Stasiuk, deux écrivains polonais à fronts renversés? ", Recherches \& Travaux [En ligne], 80 | 2012, mis en ligne le 15 novembre 2013, consulté le 08 septembre 2020. URL : http://journals.openedition.org/recherchestravaux/526 ; DOI : https:// doi.org/10.4000/recherchestravaux.526 


\section{Ryszard Kapuściński et Andrzej Stasiuk, deux écrivains polonais à fronts renversés?}

Imperium $^{\mathrm{I}}$ de Ryszard Kapuściński a été récompensé du prix de la Foire du livre de Leipzig en 1993, Sur la route de Babadag² d'Andrzej Stasiuk a remporté le prix Nike (équivalent du Goncourt en Pologne), alors qu'il était en compétition avec un autre livre de Kapuściński, en $2004^{3}$. Et pourtant, ces deux auteurs s'ignorent. À ma connaissance, aucun des deux ne cite l'autre dans son œuvre. Ce sont en premier lieu leurs choix de vie qui les séparent. Non seulement ils n'appartiennent pas à la même génération, puisque Kapuściński est né à Pińsk, en Biélorussie, en 1932, et que Stasiuk est né à Varsovie, en 1960, mais ils ont fait des choix politiques presque opposés. D'après son biographe, Artur Domosławski ${ }^{4}$ Kapuściński a été membre du parti communiste de 1954 à 198I, début de l'état de siège. Bien qu'il se défende d'avoir été très politisé dans sa jeunesse, Stasiuk a passé près de deux ans en prison pour pacifisme, après avoir déserté, durant son service militaire, au début des années 1980. Kapuściński a beaucoup vécu à l'étranger, loin de l'Europe, en Afrique, en Amérique du Sud notamment. Andrzej Stasiuk a quitté Varsovie en 1987, pour s'enraciner dans un hameau des Beskides, montagnes du sudest de la Pologne.

I. R. Kapuściński, Imperium ([1993], Varsovie, Czytelnik, 2008), trad. du polonais par V. Patte, Plon, 1994. Toutes mes références seront tirées de l'édition I0/18, 1999.

2. A. Stasiuk, Sur la route de Babadag (Wołowiec, Czarne, 2004), trad. du polonais par M. Maliszewska, Bourgois, 2007. Toutes mes références seront tirées de cette édition.

3. R. Kapuściński, Mes voyages avec Hérodote (Cracovie, Znak, 2004), trad. du polonais par V. Patte, Plon, coll. «Feux croisés», 2006.

4. A. Domosławski, Kapuściński. Le plus vrai que vrai (Varsovie, Świat Książki, 20ıo), trad. du polonais par L. Dyèvre, adapté par J. Krause, Les Arènes, 20II. Cette biographie est à utiliser avec circonspection, car elle est très controversée. 
On peut développer l'opposition en soulignant que les deux récits de voyage n'ont pas le même objet et sont inspirés par des projets fort différents. Dans la première partie de son livre, Kapuściński remonte aux années 1960, au cours desquelles il a effectué ses premiers voyages dans le Caucase, et aux années 1930 durant lesquelles sa famille a été confrontée au stalinisme. Les deux parties suivantes, qui nous intéressent ici, sont consacrées à l'effondrement de l'URSS, avec la relation du voyage effectué de I989 à I99I, puis les réflexions que celui-ci lui inspire en I992-I993. À l'opposé, les souvenirs de Stasiuk sont très peu datés. Dans le chapitre final, le lecteur apprend que l'auteur voyage depuis «sept ans environ" (p. 243) et qu'il choisit comme terminus ante quem l'hiver 2002-2003 qui précède d'un peu plus d'un an l'intégration européenne (p. 262). Autrement dit, son livre se termine alors que la transition du socialisme au capitalisme a déjà quinze ans. Les deux textes n'ont pas le même objet, ni d'un point de vue chronologique ni d'un point de vue géographique. Kapuściński souhaite «traverser l'Union soviétique, ses quinze républiques fédérées» :

Les postes avancés de ce voyage sont :

à l'ouest : la frontière avec la Pologne;

à l'est : le Pacifique (Vladivostok, le Kamtchatka ou Magadan) au nord : Vorkouta ou la Nouvelle-Zemble;

au sud : Astara (frontière de l'Iran) ou Termez (frontière avec l'Afghanistan). (p. 94)

Alors que Kapuściński parcourt l'URSS, Stasiuk reste à l'extérieur, dans son ancienne zone d'influence, certes, mais dans une aire géographique dotée, à l'époque communiste, d'un autre statut politique, celui des républiques qui avaient théoriquement conservé leur souveraineté. Stasiuk arpente, du nord au sud, "tout le fameux entre-deux-mers, entre la Noire et la Baltique» (p. IO2) : ses pérégrinations s'arrêtent à «la limite occidentale de l'Europe slave», en Slovénie (p. II7), et son incursion la plus à l'est se situe en Transnistrie, à la frontière entre l'Ukraine et la Moldavie, laquelle est le seul pays visité à la fois par Stasiuk (chap. IO, p. I59-192) et Kapuściński (p. 279-282). En d'autres termes, ses voyages embrassent une bonne partie de l'Europe centrale et balkanique.

On pourrait objecter qu'ils adoptent le même point de vue, celui de la périphérie. Kapuściński veut se décentrer par rapport à Moscou, voir les choses "depuis Khabarovsk ${ }^{5}$. Stasiuk veut se décentrer par rapport à l'Europe de

5. G. Gasyna, "The Poetics of The Bordelands : Ryszard. Kapuścinskis Poland», The Polish Review, vol. LIII, $\mathrm{n}^{\circ}$ I, 2008, p. 53-72. Le décentrement du point de vue, chez R. Kapuściński, est le sujet de l'article de G. Gasyna, qu'il conclut en suggérant de comparer Busz po polsku (Bush à la polonaise, 1962, non traduit) aux Contes de Galicie (1995) d'A. Stasiuk. 
l'Ouest, et plus largement l'Occident. Le premier veut suivre des événements politiques, voire leurs prolongements militaires - il se rend sur différents lieux de conflits, comme l'Abkhazie (p. I37) ou le Haut-Karabakh (p. 240), ce qui permet d'inclure des épisodes héroïques. Il adopte la posture du grand reporter «baroudeur». Dans le second chapitre de Sur la route de Babadag, Stasiuk établit aussi un lien entre voyage et politique : «Tout a commencé avec la guerre des Balkans. [...] Je voulais tout simplement savoir sur quoi tirait l'artillerie et ce que voyaient les pilotes d'avion" (p. I8). Mais cette déclaration d'intentions est quelque peu trompeuse, parce qu'il ne se rend pas en ex-Yougoslavie pendant la guerre et que ses pas le conduisent une seule fois dans l'un des pays issus de son éclatement, en Slovénie, au huitième chapitre ${ }^{6}$. Ce ne sont ni les opérations militaires et diplomatiques, ni les processus politiques que cherche à comprendre le voyageur polonais, mais les questions anthropologiques. À la différence de Kapuściński, il adopte, pour ainsi dire, une posture antihérö̈que, visitant des régions en paix, le plus souvent à l'écart de tout événement quel qu'il soit, notamment parce qu'il préfère les campagnes reculées aux villes (p. 286-287). Ce choix ne souffre qu'une seule exception, très révélatrice : l'incursion en Moldavie - et tout particulièrement en Transnistrie. Quant au choix d'arrêter son récit avant mai 2004, il se révèle moins politique que métaphysique : Stasiuk est un écrivain de la mélancolie, sur les traces d'un monde qui va disparaître, dans une acception beaucoup plus large que la disparition du seul système communiste. Son récit est placé sous le signe de la perte tandis que celui de Kapuściński est placé sous celui de la métamorphose. Ce dernier vient vérifier si la grille de lecture que lui fournit son expérience de la décolonisation dans le tiers-monde permet d'interpréter les événements qui bouleversent l'URSS : «[...] ce qui m'intéresse avant tout, c'est la décolonisation du monde, sur le plan politique et psychologique. Or ce processus était justement en cours en Transcaucasie» (p. 319). L'autre versant de sa réflexion est sans doute éclairé par une problématique assez typiquement communiste : l'effondrement de l'imperium est-il un processus révolutionnaire? En revanche, Stasiuk veut "sauver des faits du néant», des lieux et des gens, parfaitement obscurs, de l'inexistence à laquelle les voue le fait qu'ils soient hors de tout champ médiatique, hors du champ de l'occidentalo-centrisme.

Est-ce que la différence d'objet historique et géographique explique à elle seule les divergences entre les deux livres? Y-a-t-il des points sur lesquels ils se rejoignent? Ceux-ci permettraient-ils de définir un "point de vue polonais» sur l'effondrement de l'empire? Pour évaluer l'écart entre les deux œuvres, il

6. En revanche, dans Fado (Wołowiec, Czarne, 2006), trad. du polonais par C. Zaremba, Bourgois, 2008, le chapitre 3 raconte une rencontre littéraire au sujet des écrivains D. Kiš et Bulatović, à Belgrade, et le chapitre 7 relate un court séjour au Monténégro. 
faut partir de la phénoménologie de la Transition qu'elles proposent. Partant de leurs constats respectifs, on s'aperçoit que le grand reporter propose une analyse fondée sur l'analogie, tandis que l'effondrement de l'Empire soviétique permet à l'écrivain des Beskides de retrouver la mémoire de deux empires antérieurs : l'austro-hongrois et l'ottoman. Malgré les tentatives d'explication assez nettement orientées de la part de Kapuściński, les deux livres dessinent peut-être des positions à fronts renversés : Kapuściński semble développer un point de vue à la fois anti-stalinien, très polonais et occidentalo-centré, tandis que Stasiuk part sur les traces de révoltes prémarxistes, fait entendre la voix des "ostalgiques», donne la charge contre les méfaits de la mondialisation et de l'occidentalisation, tout en maintenant que le dernier mot de l'existence humaine ne peut être politique.

\section{Une phénoménologie de la Transition?}

\section{Deux moments}

Kapuściński et Stasiuk sont les témoins de deux moments très différents. Le premier assiste au moment où l'Empire soviétique s'effondre, où tout s'accélère, où le changement se caractérise par une rapidité et une puissance symbolique quasi révolutionnaires. Le champ lexical nous mène de la mort imminente - «[...] le communisme vivait ses dernières heures» (p. 93) - à la mort effective :

C'est une période transitoire. Tout s'explique aujourd'hui par ces mots magiques. Le communisme s'est désintégré. (p. 285-286)

Le récit n'est pas toujours clairement daté, ni complètement linéaire. Il faut démêler notamment la chronologie des événements, connus de tous, de celle des déplacements du reporter. C'est dans les pages consacrées à la révolution ukrainienne que celui-ci multiplie les dates, mimant de la sorte un singulier effet d'accélération : le I6 juin I99I, le Parlement proclame la souveraineté de la RSSU; le I9 août a lieu une tentative de coup d'État à Moscou, qualifiée par l'auteur de "putsch néo-stalinien »; le 24 août, le Soviet suprême de l'Ukraine déclare la création d'un État ukrainien indépendant. Pourtant, la narration ne progresse pas en ligne droite, mais au gré des analepses du narrateur. Celui-ci assiste au déboulonnage de la statue de Lénine à Kiev, le 3I août I99I (p. 286), puis se rappelle un séjour antérieur durant l'été I990 (p. 287), et un autre en janvier I990, peu après la formation d'une chaîne humaine de cinq cents kilomètres pour célébrer l'anniversaire de "l'éphémère indépendance de l'Ukraine en 1918» (p. 289). Bien que Kapuściński revendique à plusieurs reprises la volonté d'écrire sur la vie quotidienne des 
citoyens ex-soviétiques et non sur l'histoire événementielle, il semble tout de même s'efforcer d'être présent aux grands événements. S'il arrive quelques jours en retard à Moscou - le 25 et non le I9 août - juste à temps pour assister aux funérailles des trois victimes russes du putsch (p. 326) et à Kiev - le $3 \mathrm{I}$ et non le 24 août -, il parvient aussi à se trouver sur les lieux au moment de l'action :

Les chars du KGB donnent l'assaut à une manifestation pacifique à Vilnius. Bilan : une quinzaine de morts, des dizaines de blessés. Les Lituaniens entourent leur Parlement d'un barrage de béton. Lorsque j'y pénètre, j'ai l'impression de me trouver à l'intérieur d'un château assiégé [...]. (p. 325)

Le journaliste avoue qu'il est encore plus difficile de suivre le mouvement intellectuellement que physiquement :

Le monde vit une phase d'histoire chaude, en particulier à la périphérie de l'empire :

Les frontières de l'ex-URSS sont une véritable bombe à retardement. Entre I92I et 1980, les républiques fédérées ont procédé entre elles à plus de quatre-vingt dix modifications territoriales et révisions de frontières. En I990, il existait entre ces républiques plus de cinquante conflits territoriaux. Aujourd'hui le nombre de ces litiges est sensiblement plus important. (p. 337)

Dans le chapitre intitulé "Le piège» (p. 240-263), Kapuściński ménage un véritable coup de théâtre : il revient sur son séjour dans le Caucase, pour intercaler un épisode autocensuré dans son récit antérieur :

Cette histoire s'est passée l'été 1990. Je ne l'ai pas racontée plus tôt afin de ne pas exposer à la répression les personnes qui m’avaient aidé. (p. 240)

Il raconte comment, avec l'aide d'une députée arménienne, il a pu se rendre clandestinement dans le Haut-Karabakh, en pleine période de conflit entre l'Azerbaïdjan, peuplé de turcophones chiites, et cette enclave d'Arméniens chrétiens, qui réclament leur rattachement à l'Arménie, distante de seulement treize kilomètres. Pour pénétrer dans ce théâtre de guerre, puis le quitter, le reporter doit se déguiser en pilote d'avion, se faire passer pour russe, et feindre d'être saoul. L'art du suspense et de la dramatisation sous-tend cet épisode :

La ville [Erevan] est pleine de fedayin; dans les rues, au volant de camions, armés de bric et de broc, habillés n'importe comment, mais tous barbus. (p. 242)

Contrairement à ce que suggèrent la géographie et l'histoire, le récit de voyage de Stasiuk n'est pas simplement complémentaire de celui de Kapuściński. Il repose sur des principes radicalement différents. Kapuściński accorde de l'importance à la chronologie et aux événements, sans doute parce qu'il a eu une formation d'historien. Stasiuk s'y montre indifférent, voyage 
sans prendre de notes, se documente plutôt au retour de ses voyages qu'avant le départ, écrit de mémoire. Son écriture, résolument subjective, obéit aux caprices de l'oubli et des réminiscences. Le récit est non linéaire, superpose de multiples voyages dans les mêmes lieux, simplement datés par des indications de saison et une chronologie relative. Jamais il ne mentionne la fin du communisme en Pologne avec les premières élections libres de juin I989, ni la chute du Mur de Berlin en novembre 1989, ni la fin officielle de l'URSS le 25 décembre 199i. Seuls les realia nous indiquent qu'il voyage après l'effondrement de l'Empire : il passe les frontières presque toujours facilement. Il est question, une seule fois, d'une «PGR hongroise» (p. 328) - comprenez « une ferme collectivisée». La seule exception, révélatrice, est la Moldavie. Est-ce un hasard si les séquelles de la domination soviétique sont plus nombreuses dans un pays qui faisait partie de l'URSS, et non pas dans les démocraties populaires du pacte de Varsovie? Celui-ci évoque l'architecture de béton, «le gris lichen post-soviétique» (p. I66), puis le «design post-soviétique», à la frontière entre la Moldavie et un "pays inexistant», la Transnistrie sécessionniste (p. 179). La trame événementielle est réduite à deux dates qu'il nous faut reconstituer : 199I et 2004. Au chapitre 2, Stasiuk associe son désir de voyager au début de la guerre des Balkans (p. 18). Au chapitre 8, il nous rappelle que c'est en Slovénie que les hostilités ont commencé, en I991. Mais il s’y rend en $200 \mathrm{I}$ :

Le douanier m'avait demandé combien de dinars j'avais sur moi, alors même que, depuis dix ans déjà, on y payait en tolars. (p. I25)

Il faut ensuite attendre le dernier chapitre du livre pour apprendre qu'au moment où il achève la rédaction, il voyage depuis environ sept ans et qu'à un an de là, le poste frontière voisin de Konieczna, par où l'on passe de Pologne en Slovaquie, sera aboli pour cause d'intégration européenne (p. 262). On dirait que l'écrivain voyageur fuit l'événement. Il prend soin de venir aprèscoup en Slovénie, mais aussi en Moldavie, où il voyage, là encore, une dizaine d'années après la guerre de sécession de I99I-1992, ou alors avant, lorsqu'il effectue un demi-tour sur le parking de Konieczna, un jour où la neige abolit, avant les traités, le tracé de la frontière. Stasiuk joue beaucoup sur l'implicite, l'énigme, et propose plusieurs devinettes à son lecteur : lors d'une traversée de la Hongrie, il fête le cent-soixante-neuvième anniversaire de la naissance de l'empereur François-Joseph (p. 83), un I8 août - ce qui nous place en 1999. $\mathrm{Au}$ "j'y étais» de Kapuściński, Stasiuk oppose un retentissant «je n’ai pas vu le rideau de fer tomber». Tel est en effet le titre d'un des rares articles que ce dernier ait donné à la presse française, dans Libération du I2 mars 2009, à l'occasion du vingtième anniversaire de la chute du Mur de Berlin : 
Je regardais de loin les changements, toute cette révolution. Un peu comme si elle avait lieu dans un autre pays. Avec le recul de ces vingt années, je me rends compte que je ne m'y suis pas vraiment intéressé. Je n'y ai pas pris part.

Sa chronologie est celle du retentissement concret de l'Histoire sur les vies individuelles. Pour lui, l’effondrement a eu lieu dans les années 1980, alors qu'il vivait à Varsovie :

[...] nous étions excités par la chute du communisme, par l'atrophie absurde et pittoresque du système $[\ldots]$, peut-être pressentions-nous que rien ne serait plus jamais aussi joyeux et décadent [...], mais aucun d'entre nous n'était capable d'imaginer ce qu'il y aurait après.

Ensuite, une fois installé dans son "village des Carpates», les gardesfrontière cessent de contrôler l'identité de ses invités, puis, second signe, en 1992, son premier livre, Les Murs d'Hébron', inspiré par son séjour en prison, est publié. Se tenir à l'écart de l'histoire, c'est se protéger de la violence, vivre selon une autre temporalité, celle de la longue durée. L'article, dans la belle traduction de Charles Zaremba, se clôt pour ainsi dire sur une posture anti-journalistique :

Mon Dieu - je n'ai pas vu à la télévision le mur de Berlin se fissurer, je n'ai pas vu le putsch de Moscou, je n’ai pas vu la révolution de velours de Tchécoslovaquie $[\ldots .$.$] j’ai eu de la chance et rien ne m’a empêché de lire les Pères du désert, de$ traire mes chèvres et de me saouler à mort avec les bûcherons.

\section{Transition politique et culturelle}

Les deux voyageurs font apparemment un constat similaire : ils sont confrontés à un flux de paroles. Cela inspire à Kapuściński quelques morceaux de bravoure, où sa verve humoristique trouve à se déployer :

Cette époque est le paradis des discuteurs, des tribuns, des polémistes, des bavards, des prêcheurs, des orateurs, des escrimeurs verbaux et des chercheurs de vérité. (p. 229)

Il n'est évidemment pas possible de citer in extenso les pages que lui inspire "la parole débridée» de l'intelligentsia moscovite (p. IO3, 229). Le reporter établit explicitement des liens de cause à effet. La libération de la parole en URSS a une explication politique :

Pour moi, la perestroïka a été l'association de deux grandes expériences que la société soviétique a vécues :

- une cure massive de désaccoutumance à la peur ;

- un voyage collectif au pays de l'information. (p. 323)

7. A. Stasiuk, Mury Hebronu (Les Murs d'Hébron) [1992], Wołowiec, Czarne, 2009, non traduit. Je remercie A. Jasińska et A. Marek pour m’avoir aidée à déchiffrer certaines sources en polonais. 
En effet, non seulement les Russes se parlent entre eux, mais ils lui parlent. Cette ambiance contraste de manière saisissante avec la chape de silence que l'auteur à connue dans son enfance et qu'il évoque dans la première partie d'Imperium. Les conversations que retranscrit Kapuściński ont indéniablement la tournure d'interviews, de témoignages très adressés, chargés d'intentions, ce qui suggère que leur interlocuteur ne s'est pas présenté à eux comme un simple voyageur. Lorsque celui-ci restitue sa conversation avec les Arméniens de Stepanakert, le cadre journalistique est explicite :

La soirée se passera en conversations. C'est bien pour cela que je suis venu. Je suis ici pour rencontrer des gens du comité du Karabakh, des gens qui ne peuvent pas sortir d'ici, qui sont condamnés au mutisme, à une résistance silencieuse, et qui voudraient faire connaître au monde le destin des Arméniens de cette région, leur infortune, leur drame. (p. 253)

Parfois cette parole s'efforce de résumer en une forme brève et concentrée toute une vie - confession, philosophie de la survie durement acquise (p. 277) - et alors, le journaliste se retrouve dans un autre rôle, entre le scribe et l'écrivain, chargé d'une mission existentielle et non plus politique : relayer (avec quel coefficient de réécriture?) la parole des gens obscurs, leur permettre de laisser une trace.

Stasiuk rencontre aussi beaucoup d'autochtones volubiles, mais ceux-ci semblent ignorer qu'il est écrivain. Il s'agit toujours de paroles qui sont adressées à lui et à ses compagnons de voyage, de manière manifestement désintéressée, d'ailleurs souvent exprimées dans une langue qu'il ne comprend pas. Par la force des choses, presque toutes les conversations relatées dans Imperium se déroulent en russe. Mais il est frappant que Stasiuk et ses interlocuteurs qui, pour la plupart, ont subi l'enseignement du russe à l'école, à l'époque soviétique, évitent le recours à cette langue, quitte à communiquer dans un sabir babélien, parfois du "panslave», y compris en Hongrie (p. 82), en Albanie (p. I5O-I5I), parmi les enfants tsiganes de Roumanie (p. II3-II5). Les rares locuteurs russophones se trouvent en Moldavie (p. 165, I88) et dans le delta du Danube, en Roumanie ${ }^{8}$ (p. 225). L'épisode le plus caractéristique a lieu dans une gargote tenue par une Grecque, en Albanie, et l'histoire ne dit pas dans quelle langue se passe le "dialogue»:

Elle ne voulait pas d'argent. Elle voulait bavarder, elle voulait parler. Il lui importait peu de savoir que nous étions obligés de deviner le sens de ce que nous nous disions. (p. I5I)

8. Cl. Magris, Danube (Danubio, Garzanti [1986]), trad. de l'italien par J. et M.-N. Pastoureau, Gallimard, I988, p. 546. Il s'agit sans doute de Lipovènes, vieux-croyants arrivés de Russie au XVIII ${ }^{\mathrm{e}}$ siècle. 
Contrairement à son aîné, Stasiuk ne propose pas d'explication, il livre le phénomène à l'état pur, sous la forme d'une énigme, laissant à son lecteur le soin d'échafauder des hypothèses. Une anecdote suggère une piste politique. Pour plusieurs autochtones, le voyageur est probablement le premier étranger qu'ils rencontrent. Leurs questions trahissent l'enfermement dont leur pays a été victime, non seulement sous la dictature de Ceauşcescu ou Hodja, mais probablement depuis bien plus longtemps, faute de moyens de communication modernes. Genci, un Albanais converti à l'évangélisme et s'exprimant dans « un anglais impeccable» demande : "En Pologne, il y avait le communisme?» (p. I47). Le contexte est souvent celui de l'hospitalité, et la parole apparait alors, au même titre que les mets et les alcools, comme un don codifié et généreux, à lire plutôt à la lumière de l'anthropologie. Mais pour l'essentiel, Stasiuk laisse dominer l'expérience de l'incompréhension. Ce choix d'écriture - ou cette fidélité à ce qui a été vécu - vient étayer l'un des motifs récurrents du livre, celui de la solitude existentielle de l'homme. Il faut prêter attention au leitmotiv du récit : «L'Albanie, c'est la solitude» (p. I54), ou bien encore à la conversation métaphysique avec une paysanne roumaine, qui élève des animaux en dépit de toute rationalité économique pour contenir «l'angoisse face à la solitude du genre humain» (p. IOI).

Pour en revenir à la lecture politique de Kapuściński, signalons que la levée de la peur et la transparence de l'information n'ont pas seulement une incidence sur la parole. Plusieurs anecdotes spectaculaires illustrent l'idée qu'elles modifient profondément les comportements. Ainsi, à peine arrivé à Erevan, Kapuściński assiste à la retransmission de débats du Soviet suprême, durant lesquels Mikhail Gorbatchev se fait molester sans que son agresseur soit ensuite inquiété (p. 320). C'est à la périphérie de l'empire que se manifestent les plus importantes transgressions de l'ordre impérial. Kapuściński croise pour la première fois d'autres hommes armés que ceux de l'Armée rouge, laquelle semble non seulement impuissante à empêcher le conflit entre Arméniens et Azéris (p. 320), mais incapable de procéder à un banal contrôle dans un car où, soudain, les passagers Arméniens et Géorgiens font bloc contre les soldats (p. I27). Cette liberté aux confins contraste avec la persistance, au Kremlin, d'un contrôle digne de la guerre froide. Ryszard Kapuściński raconte avec verve, en usant du comique de répétition, comment il se heurte, quelle que soit sa direction, à un tandem d'hommes «bien bâtis, en complet gris» (p. 236-237). Le changement est aussi perceptible sur le plan symbolique, avec l'élimination de «toute la symbolique russe et soviétique" (p. I2I, 284), ainsi qu'à travers le vaste mouvement de restitution des églises. La transition culturelle est presque aussi rapide que celle au niveau politique. On ne dit plus "camarade», sans oser revenir au "monsieur» de 
l'époque tsariste: "Aussi utilise-t-on les mots "homme", "femme"." (p. I42) Un écrivain azéri avoue ne plus écrire, parce que son peuple n'a plus d'alphabet. Ils ont renoncé au cyrillique, sans avoir encore choisi entre le latin et l'arabe (p. I49).

\section{Transition économique et écologique}

La transition économique et écologique est nettement moins euphorique. L'URSS connaît toujours un régime de pénurie : savon introuvable à Erevan (p. I25); ruée sur un arrivage de poissons (p. I26), de gâteaux industriels (p. 196) ou de chaussures (p. 275); rareté de la viande à Kiev (p. 283). Kapuściński résume ainsi la situation : "L'homo sovieticus est avant tout un homme exténué.» (p. 285) Celui-ci emploie toute son énergie à s'approvisionner, à s'adapter aux coupures d'eau. La situation décrite par Stasiuk est plus complexe car réellement transitoire. Les modes de production, ou du moins d'échange, se sont transformés, avec la liberté de circuler et de commercer. S'il reste quelques articles typiques de l'époque soviétique, c'est à titre résiduel, comme les Jigouli et autres Moscvitchs, vieux modèles d'automobiles qui circulent encore en Moldavie. Non sans humour, l'auteur laisse commenter la mutation par un baron tsigane de Moldavie, très doué pour l'euphémisme :

Cela mis à part, ça allait, les frontières étaient pratiquement ouvertes, on pouvait voyager, faire des affaires, il fallait juste avoir un passeport, des idées et des relations. Si quelqu'un le souhaitait, il pouvait se rendre chez les Tchouktches ${ }^{9}$ et leur vendre ses sous-vêtements chinois. Personne ne l'interdisait. Autrefois, ce n'était pas mal non plus, mais les opportunités étaient moindres. (p. 190)

En grand passeur de frontières - «cent-soixante-sept en sept ans environ" (p. 243) -, Stasiuk évoque les diverses formes d'économie frontalière générées par le passage au libéralisme. Il décrit une économie légale, de recyclage des objets de l'Ouest à l'Est - épaves de voitures allemandes en Albanie (p. I34I36) -, d'échange d'électroménager de qualité occidentale, de la Hongrie vers l'Ukraine (p. 95), contre des produits bon marché fabriqués plus à l'est, au marché d'Ubl'a, toujours à la frontière ukrainienne (p. 293). La seule frontière qui compte et se renforcera après 2004 est celle de l'économie et de l'espace Schengen. Il évoque aussi de manière très suggestive une économie illégale qui semble relayer les formes connues du marché noir à l'époque soviétique : " cinq autocars avec dix tonnes de marchandise de contrebande" à Siret, sur la frontière roumano-ukrainienne (p. 53), trafic de devises en Albanie (p. 139). Pourtant, Stasiuk n'accrédite nullement le cliché de la corruption

9. Peuple de Sibérie qui joue le rôle des naïfs de la campagne dans les blagues russes. 
généralisée. Il livre plusieurs anecdotes qui attestent, au contraire, de l'honnêteté et de la bienveillance de nombreux douaniers (p. 93-96), cheminots (p. 78-79), chauffeurs de taxi (p. 57-60) et autres anges gardiens (p. 62, 79, $80,195)$, qui veillent sur la tradition de l'hospitalité. Une douanière albanaise corrompue fait exception (p. I38), ainsi qu'une bonne partie de l'économie moldave. Comme à son habitude, Stasiuk s'en tient à la description : "or, lunettes noires, look à la mode, quelque part entre trafiquant de devises, maquereaux et lovers italiens, [...], des petits malins dans leur Land Cruiser regardant la rue comme si elle leur appartenait [...]»(p. 174). Tels sont les nouveaux riches d'une économie notoirement mafieuse qui peuplent les rues de la capitale. Sur ce point, la démarche de Kapuściński est tout autre : il faut sinon dévoiler la cause, du moins faire l'archéologie du phénomène - «cette obsession de la mafia» remonte aux années 1920 (p. 209) - voire en faire le décodage idéologique :

À l'heure actuelle, le mot «mafia» fait une carrière fulgurante. De plus en plus souvent, il remplace le mot "peuple». (p. 208)

Kapuściński s'efforce de théoriser son expérience : «La scène politique tourne bien plus vite que la scène de notre vie quotidienne.» (p. 330) Il prédit que si aucune amélioration économique ne relaie la transition politique, c'est la promesse de démocratie qui sera compromise en retour :

Cette année de déceptions a suffi à gâcher l'atmosphère politique du pays.

[...] Ce climat favorise le renforcement de méthodes de gouvernement autoritaires, encourage toute forme de dictature. (p. 335-336)

Écrivant ces pages en 1992-1993, années de chaos en URSS, il apparaît comme un pessimiste qui porte un regard anxieux sur l'avenir. En revanche, Stasiuk jouit d'un recul historique d'une quinzaine d'années. Le bilan de la conversion au capitalisme est assez négatif : économie de pays pauvre qui exporte ses travailleurs immigrés (p. 155) et vend ses organes (p. 246). Stasiuk ne désavouerait sans doute pas le propos du cinéaste Ken Loach, dans son film au titre ironique, It is a free world (2007), consacré à l'exploitation des travailleurs clandestins de l'Est en Grande-Bretagne. Il a également repris le thème de la marchandisation généralisée dans une tragi-farce publiée un an après Sur la route de Babadag, parue sous le titre français Les Barbares sont arrivés $^{10}$. Les rares dates qu'il fournit sont celles d'une chronologie désastreuse : pathétique exode des Albanais en 1992 (p. 135), anarchie et désespoir du même peuple, après l'écroulement des pyramides financières en 1997 (p. $156-158)$.

IO. A. Stasiuk, Les Barbares sont arrivés (Wołowiec, Czarne, 2005), trad. du polonais par Z. Bobowicz, éditions Théâtrales, culturesfrance, 2008. 
Kapuściński et Stasiuk s'accordent largement sur l'héritage écologique, avec cependant des thèmes et des approches différents. Le problème de l'eau est le fil conducteur d'Imperium, avec deux chapitres consacrés à la question. "Pour demain, la révolte des Bachkirs» raconte une intoxication de l'eau au phénol, à Oufa, capitale de la Bachkirie (p. I72-I80) et "Asie centrale, l'extinction d'une mer" l'assèchement de la mer d'Aral (p. 264-274). Toujours est-il qu'il n'a de cesse d'informer ses lecteurs du processus politico-économique dont résulte la pollution. Et dans les deux cas, il repère une analogie avec le fonctionnement colonial : «[...] les unions de type "agrochimie" ou "chimie", ici légion, ne sont pas sans rappeler l'“Union minière" » du Katanga ou la "Miferma" de la Mauritanie» (p. I78), écrit-il à propos de la Bachkirie. Dans le second cas, le régime soviétique a imposé en Ouzbékistan le remplacement des cultures vivrières par le coton, qu'il a fallu irriguer : "Situation coloniale typique : la colonie fournit la matière première que la métropole transforme en produit manufacturé» (p. 269). Chaque fois, l'analyse pourrait déboucher sur une lutte. Stasiuk procède autrement. Il n'explique pas, ne désigne pas de responsable, mais suscite assurément la révolte esthétique de son lecteur par un traitement très inspiré de la laideur postindustrielle. Le premier exemple concerne les anciennes mines d'or de Baia Mare (Roumanie). Tout le texte repose sur la tension entre les vestiges menaçants de l'industrie et l'apparente reconquête par la nature, illusion que ruine impitoyablement la chute du mouvement : "[...] des chevaux [...] broutaient sans répulsion l'herbe empoisonnée» (p. 99). Stasiuk ne date pas le site industriel, pas plus qu'il ne précise si le site métallurgique de Krompachy (Slovaquie) est encore en activité ou pas : «Rouille, misère du métal mort et désespoir de la technologie en dépérissement» (p. 30I). En revanche, les cimetières de voitures en Albanie sont explicitement le résultat de la transition économique, et inspirent une saisissante métaphore filée de la maladie :

[...] une gangrène de câbles de freins, un cancer de dalles de plancher, une syphilis de joints et un leucome de vitres lézardées. Oui, les faubourgs de Dürres, c'était l'immense hôpital de campagne du parc automobile allemand [...](p. 135)

À la différence de Kapuściński, dont le style est pugnace, l'approche argumentée, Stasiuk semble exprimer un calme désespoir. Les habitants de ces contrées, souvent des Tsiganes - ne se révoltent pas, sont résignés. Ceux qui sont conscients, comme l'ami albanais, Astrit, sont accablés par une pollution indestructible :

[...] dans tout le pays, il n’y [a] pas une seule aciérie en état de fonctionnement pour faire fondre ces déchets allemands. Il n'y a pas non plus assez d'explosifs pour faire sauter les soixante mille blockhaus [construits par Hodja] qui devaient résister à l'assaut mondial. (p. I36) 
Pour une fois, le pathétique domine chez Stasiuk, tandis que Kapuściński clôt son chapitre consacré à la mer d'Aral sur le grotesque et l'absurde de la bureaucratie encore soviétique, qui paie une armée de fonctionnaires à étudier la possibilité de rediriger les fleuves sibériens vers l'Ouzbékistan! (p. 274)

Au bout du compte, malgré la différence de moment, les tableaux de la transition économique ne sont pas aussi contrastés que l'on pouvait s'y attendre. Ils sont dominés par l'absence d'euphorie. Pour répondre à la question initiale - nos deux textes proposent-ils une phénoménologie de la Transition? - force est de constater que Stasiuk est plus phénoménologue, et Kapuściński plus pédagogue. Imperium est, entre autres, un documentaire très dense, fournissant des explications, sous-tendu par un positivisme, une foi dans la connaissance, tandis que Stasiuk sollicite une forte participation de son lecteur qu'il confronte à la dimension énigmatique du voyage.

\section{Défunts empires : de l'analogie à la mémoire retrouvée}

\section{La décolonisation dans Imperium}

Comme le suggère l'analyse de l'héritage écologique, Kapuściński dispose bien d'une grille de lecture qui consiste à repérer des analogies entre l'effondrement de l'URSS et la décolonisation du tiers-monde. Il ne nie pas que l'analogie avec Rome ait joué un rôle dans le destin impérial de la Russie, en raison de sa place dans l'imaginaire collectif. C'est pourquoi l'origine de la formule «Troisième Rome» est l'une des premières choses qu'il rappelle :

Cette idée fut avancée dès le $\mathrm{XvI}^{\mathrm{e}}$ siècle par Philotée, moine de Pskov, le sage et le visionnaire : «Deux Romes sont déjà tombées (celle de Pierre et celle de Byzance), écrivait-il dans une lettre au prince de Moscou, Vassili III. La Troisième est debout.» (p. 99)

Mais il se tourne résolument vers des fins d'empires beaucoup plus récentes pour tenter de comprendre les bouleversements auxquels il assiste :

Ce n'est pas la peine d'aller chercher bien loin, dans l'histoire de Rome, ou celle de la Turquie, pour s'en convaincre. Il suffit de prendre un exemple plus récent, que j'ai connu personnellement : l'Iran des années soixante-dix. (p. II9)

Le lecteur reconnaît l'allusion à son livre Le Shah (1982), consacré à la Révolution iranienne, et non à la décolonisation. C'est d'ailleurs l'indice d'une hésitation de l'auteur entre deux hypothèses de lecture : l'effondrement de I'URSS est-il un processus de décolonisation ou une révolution? La première analogie l'emporte, mais il n'est pas impossible qu' elle vaille principalement pour les rapports entre le centre et la périphérie, tandis que la seconde s'appliquerait au seul centre. L'analogie a d'abord une fonction pédagogique, quand 
l'auteur compare explicitement le peuple arménien aux Juifs (p. I23). Mais lorsque celle-ci devient systématique, elle prend une valeur heuristique. C'est dans sa connaissance de la décolonisation du tiers-monde déclinée à travers trois références - aux empires français, anglais et portugais - que Kapuściński puise les éléments de compréhension de la situation de l'URSS : l'Abkhazie est comparée à Antigua, ex-colonie britannique (p. I34), l'Ouzbékistan est victime du "système de l'indirect rule, imaginé et appliqué par les Anglais en Asie et en Afrique» (p. 266).

Plusieurs points vérifient son hypothèse : la politique de la langue, le tracé des frontières, le modèle de développement économique, et la psychologie sociale. La politique de russification de l'empire est un motif obsédant du livre, et permet d'indiquer l'ancienneté du processus colonial. Comme chacun sait, celui-ci n'est pas une invention soviétique mais un héritage du tsarisme : trois-cent-cinquante ans de russification en Ukraine (p. 87), trois cents ans en Bachkirie (p. 172), une politique "systématique, sauvage et acharnée» en Biélorussie (p. 313). Les exemples de découpage des frontières aberrants et fauteurs de guerre foisonnent, et sont rattachés explicitement à la politique de Staline (p. I49, 336). Le modèle de développement, par exemple en Géorgie, est celui du tiers-monde : "[...] extension violente, artificielle, de la capitale au détriment de la province qui ne cesse de s'appauvrir» (p. I29). Lorsque le voyageur arrive à Bakou, il loge dans l'appartement que lui a prêté une Russe qui a pris la fuite. Pourtant, note-t-il, "ici on ne touche pas aux Russes» (p. I44). Comment expliquer ce paradoxe? "Cela me rappelle l'Afrique dans les années soixante, $[\ldots]$ puis dans les années soixante-dix [...]»(p. I45), écritil. L’analyse de Kapuściński repose, dans ce cas, sur la psychologie sociale. Il emprunte au Tunisien Albert Memmi, dans Portrait du colonisé, l'idée que la peur du maitre est plus forte que la haine (p. I45). Mais il vient un moment de basculement dans le rapport de forces, où la peur change de camp : «En fait l'âme de notre colonisateur a été submergée par son enfer, par son enfer intérieur. Son sentiment de culpabilité, [...], s'est soudain réveillé, [...]»(p. I46).

Mais la mémoire de la Révolution de 1917 concurrence partiellement l'analogie avec la décolonisation. Plus précisément, la libération de la parole à Moscou rappelle "ce que l'on peut voir sur d'anciennes photographies de la révolution de Février I7» (p. 229). Le maniement de l'analogie trahit peut-être l'ambivalence de l'auteur. La référence à Février 17 est positive. Mais comment résonne celle à Octobre 17 ? Admire-t-il la victoire des Bolcheviks ou déploret-il l'absence de réaction des élites économiques de Saint-Pétersbourg, quand il s'interroge?

Où étaient donc tous ces hommes, que pensaient-ils, que faisaient-ils au moment où Lénine s'empara du pouvoir? (p. 306) 
Mais entre les deux termes chronologiques, Kapuściński a intercalé deux autres exemples où " des groupes de choc [...] s'emparent des points stratégiques essentiels sans faire couler de sang et presque en silence» (p. 306) : la prise du pouvoir par les fascistes en Italie et la mise en place de la Terreur en 1793. Il revient aux historiens d'apprécier la pertinence historique de tels raccourcis, mais l'entrelacement des références positives et négatives ne laisse pas d'être troublant, alors que celle à la décolonisation est beaucoup moins ambiguë.

\section{Les références à l'Afrique chez Stasiuk}

La posture de Stasiuk est assez éloignée de celle de Kapuściński, du fait que l'écrivain polonais n'a pas l'ambition de proposer une explication des événements : il ne faut pas "tenter d'être plus savant que [les événements]» (p. 198). Il préfère «raconter toutes ces futilités, pondre toutes ces légendes qui permettent de se reposer de la réalité qu'[il est] incapable de comprendre et que, du reste, [il] n'essaie même pas de comprendre» (p. 254-255).

Dans ce contexte, comment interpréter les références, discrètes mais récurrentes, à l'Afrique? Elles relèvent plus souvent de l'esthétique que de la politique. Ainsi, à Răşinari, le village natal de l'écrivain roumain Emil Cioran, le voyageur trouve que règne "une lumière africaine» (p. 34). Traversant la Slovénie, il effectue un nouveau rapprochement entre l'Afrique et les Balkans : "Le maréchal Tito en uniforme blanc, au milieu des palmiers sur la promenade du Portrože voisin, devait ressembler à un cacique africain.» (p. I30) Ces références sont sans doute moins une tentative d'explication par l'analogie politique qu'un usage quasi performatif de la comparaison. Il ne s'agit plus, comme chez Kapuściński, de dénoncer un système où, cependant, chacun reste dans son rôle - le Russe dans celui du colon blanc et les Caucasiens dans celui des hommes de couleur colonisés - mais de "décoloniser" l'homme blanc centre-européen, en s'attaquant à son orgueil racial. Stasiuk, qui partage avec Kapuściński un antiracisme viscéral, n’élude pas le passé ni le présent racistes de l'Europe centrale. Son récit ne revient jamais sur la Shoah, mais il mentionne avec autant de détermination que de sobriété toutes les synagogues ruinées qu'il croise sur son chemin. Il note aussi les occasions où il croise des «boules à zéro». Sa vigilance s'exerce généralement sur le mode allusif, sauf dans un passage où il prend explicitement parti pour les Tsiganes, pour ce peuple qui «même lorsqu'il finit par construire quelque chose, le fait comme s'il devait l'abandonner sur le champ, [...] et transporter son pays mobile quelque part plus loin où la canaille européenne exhale moins la haine» (p. 248). Dans un premier temps, Stasiuk souligne les analogies entre les blancs centre-européens et les peuples colonisés du tiers-monde, à partir de 
la lecture des cartes et de l'examen de leurs frontières. Dans le texte qui nous occupe, l'auteur décrit celle qui sépare la Moldavie de l'Ukraine, "une simple ligne géométrique»: "Toutes proportions gardées, sur la carte, cette frontière avait quelque chose des frontières sur le Sahara en Afrique.» (p. I84). Le chapitre avance deux types d'explication : l'une soviétique - "Ils l'ont tracée suivant les frontières des sovkhozes et des kolkhozes [...].» (p. I84) -, l'autre impériale, pour reprendre les catégories chères à Kapuściński : "Il se peut que le Géorgien ait tout prévu et planifié. Qu'il ait prévu l'éclatement de son empire fou de façon à provoquer le plus de confusion possible.» (p. I8I) Lauteur fait ici allusion aux lointaines conséquences du découpage des frontières par Staline en 1945 : adjoindre l'enclave de Transnistrie, industrielle et peuplée de Russes ou d'Ukrainiens russifiés, à la Moldavie agricole et principalement romano-slave, comme la Roumanie, a abouti, en I992, à une guerre de sécession menée par les séparatistes transnistriens. Cette situation n'est pas sans rappeler un autre cas d'école qu'est l'exemple du Haut-Karabakh, traité par Kapuściński (p. 240-263). Cependant le cas de la Moldavie pourrait laisser croire que cette situation "coloniale» ne concerne que les républiques incluses dans l'URSS, à l'exclusion des démocraties populaires, censées être plus autonomes, en Europe centrale. Or, dans Mon Europe, un essai antérieur, Andrzej Stasiuk repère impitoyablement deux autres pays concernés par le symptôme colonial des frontières géométriques : la Pologne et la Roumanie ${ }^{\mathrm{II}}$ ! Est-ce à dire qu'à défaut d'une révision des frontières, qu'il est loin de demander, I989 aurait marqué le début de la décolonisation des esprits? Fort éloigné de l'euphorie d'un grand nombre, Andrzej Stasiuk pointe très vite le phénomène que certains appellent le «troc d'empire». À peine libérés de l'hégémonie soviétique, les peuples centre-européens s'enivrent du poison de la consommation et de l'occidentalisation, non sans emprunter skateboards et casquettes de rappeurs à ceux que l'auteur désigne comme «leurs frères noirs» (p. 9I, 260), nous permettant ainsi de savourer l'ironie de la situation. En définitive, si Stasiuk recourt, furtivement, aux analogies avec les situations coloniales, c'est pour opérer une inversion des rôles. Est-ce à dire qu'il y aurait à ses yeux des analogies plus pertinentes que celles-ci?

\section{Mémoire de l'empire austro-hongrois}

Les références à l'empire austro-hongrois, assez nombreuses sous sa plume, ne doivent pas nous induire en erreur. Tout d'abord, ces allusions ne se concentrent pas exclusivement sur la fin de cet empire. Seules deux réminiscences littéraires renvoient peut-être à cette période. La première surgit à l'évocation

II. Y. Andrukhovych, A. Stasiuk, Mon Europe (Wołowiec, Czarne, 200o), trad. du polonais par M. Laurent, Montricher (Suisse), Noir sur Blanc, 2004, p. 90. 
d'Hidasnémeti, poste frontière entre la Hongrie et la Slovaquie : "C'est ainsi que devaient être les anciennes frontières aux périphéries du monde, c'est-àdire de l'Europe : le vide, le vent et les garnisons où l'on attend quelque chose, l'ennemi peut-être, et lorsque celui-ci, des années durant, ne vient pas, on se tire une balle dans la tête.» (p. 79) Parmi les grands romans européens de l'attente, Le Désert des Tartares de Dino Buzatti, Le Rivage des Syrtes de Julien Gracq et La Marche de Radetzky de Joseph Roth, seul le troisième peut être compté avec certitude parmi les lectures de l'écrivain galicien ${ }^{12}$. Sur la route de Babadag comporte une seconde allusion à l'œuvre de Roth, rien de moins que le titre du huitième chapitre, «Le pays où commença la guerre», consacré à la Slovénie, qui fait écho à un article publié dans Croquis de voyage, intitulé «Où la guerre mondiale a commencé» et datant de $1927^{13}$. Il n'est d'ailleurs pas anodin que le début de la guerre de Yougoslavie, dans la Slovénie de I99I, soit ainsi associé au déclenchement de la guerre de I4-I8, à Sarajevo. Mais à la différence de Claudio Magris, qui, en 1986, voyait dans la Yougoslavie de Tito l'héritière de l'idéal d'un état supranational jadis incarné par l'Empire austro-hongrois ${ }^{14}$, Stasiuk ne prend pas nettement parti pour l'un ou l'autre camp : les tenants de l'unité yougoslave ou ceux de l'indépendance de ses composantes. L'écho vaut sans doute davantage comme hommage littéraire que comme parallèle politique. Mais Stasiuk partage, semble-t-il, l'ambivalence de Roth. L'ironie de ce dernier, parfaitement lucide en ce qui concerne la désagrégation de la double monarchie, s'est révélée compatible avec une évolution idéologique qui l'a mené du socialisme au monarchisme. À la fin de sa vie, Roth a manifesté, face à la montée des périls totalitaires, la nostalgie pour un état supranational ${ }^{15}$. On retrouve chez Stasiuk, qui n'a cependant jamais été ni socialiste ni royaliste, à la fois l'ironie de celui qui se sent étranger à l'identité habsbourgeoise (p. I26) et la tendresse pour le monde disparu d'une possible cohabitation entre nations. Ainsi le dernier coucher de soleil hongrois, avant la frontière ukrainienne, lui inspire-t-il un fantasme de destruction à la Cioran : "Je m’imaginais que ce pourpre était la lueur au-dessus d'une Vienne en flammes, qui, pour finir, offrait à ses périphéries et provinces un ultime spectacle [...].» (p. 93) Mais Stasiuk raconte qu'il a fêté, au début de son séjour en Hongrie, le I8 août I999, le «cent-soixante neuvième anniversaire de la naissance de l'empereur François-Joseph» (p. 83). Un fou s'associe à sa beuverie :

I2. Ibid., p. I2I.

I3. J. Roth, Croquis de voyage, trad. de l'allemand par J. Ruffet, Seuil, I994, p. 322-324.

I4. Cl. Magris, Danube, ouvr. cité, p. 458.

I5. Pour une analyse plus précise du rapport de J. Roth à l'empire, voir $\mathrm{Cl}$. Magris, Loin d'où (Lontano da dove. Joseph Roth e la tradizione ebraico-orientale, Italie, I97I), trad. de l'italien par J. et M.-N. Pastoureau, Seuil, 2009, p. 19-22. 
Pouvais-je refuser? [...] Après tout, j'étais en train de voyager sur ses terres et lui [l'empereur], lors de ses audiences, recevait même les simples paysans et ne faisait aucune différence entre un Serbe et un Slovaque, ni entre un Polonais et un Roumain. (p. 83)

La référence à l'empire austro-hongrois renvoie donc moins au processus de sa désagrégation qu'à la positivité de certaines de ses valeurs. Mais, point capital, la nostalgie de Stasiuk est empreinte d'auto-ironie et la scène de libations en compagnie d'un simple d'esprit est franchement comique.

\section{Sur les traces de l'Empire ottoman}

En outre, Stasiuk opère insensiblement une redéfinition de l'identité que ses compatriotes et leurs proches voisins définissent volontiers comme celle de centre-européens, blancs, slaves et chrétiens, en montrant que leur histoire les rapproche des colonisés du tiers-monde et les rattache à une double monarchie non slave (austro-hongroise). Ce processus trouve son aboutissement dans la redécouverte des traces de l'Empire ottoman, grâce à laquelle l'écrivain polonais intègre à l'identité de cette région d'Europe l'islam et, plus largement, l'Orient.

Bien que le lecteur doive attendre la page 2I5 pour situer et comprendre le symbole que constitue la localité éponyme de Babadag, celui-ci perçoit d'emblée sa sonorité orientale et peut légitimement y déceler une intention de l'auteur: le voyage en Europe centrale et balkanique mènerait vers l'Orient. On apprend donc, dans le chapitre intitulé "Le delta», consacré à la Roumanie danubienne, que c'est à Babadag que le voyageur polonais "a vu pour la première fois de [sa] vie un minaret» (p. 215). Il ne s'agit pas d'un islam de l'immigration comme celui que nous connaissons en Europe occidentale, mais de la conversion d'ancienne date d'une partie des chrétiens orthodoxes sous la domination ottomane qui a duré près de cinq siècles. $\mathrm{Si}$ l'islam n'est plus qu'un vestige en Roumanie, il est la religion majoritaire de l'Albanie à laquelle Stasiuk a consacré le neuvième chapitre de Sur la route de Babadag ainsi que le dernier livre qu'il a publié en $20 \mathrm{IO}^{\mathrm{16}}$. Dans ce chapitre, il décrit un islam européen, où les femmes sont relativement séparées des hommes, mais où l'on boit de l'alcool : "Le raki n'est pas un alcool, le raki est une coutume.» (p. I34)

L'empreinte de l'Empire ottoman ne se limite pas à l'islam, puisque le voyageur la reconnaît en maints endroits, en dehors de l'Albanie. En Roumanie, on s'en doute, où il note : «En quittant la ville, j'avais vu trois femmes aux

16. A. Stasiuk, Dziennik pisany później (Journal écrit plus tard), Wołowiec, Czarne, 20Io, avec les photographies de D. Pawek. 
longues jupes rouges traînant jusqu'aux pieds. Certainement des Turques de la Dobroudja.» (p. 308-309) En Moldavie, dans l'enclave de Gagaouzie, il est accueilli par la minorité turcophone orthodoxe :

On ne sait pas tout à fait qui sont les Gagaouzes. [...] Ils pouvaient être aussi bien des Turcs bulgarisés que des Bulgares turquisés, mais personne n’en sait rien. (p. I66)

C'est sans surprise que la référence à l'Empire ottoman s'élargit à la catégorie de l'Orient : «faste oriental» de sa chambre chez Elena, la Gagaouze (p. I69), mais aussi «bigarrure orientale» du marché d'Ubl'a, sur la frontière ukrainienne (p. 292-293).

D'un point de vue historique, l'influence ottomane est évidente, mais il faut percevoir sa charge polémique, d'un point de vue idéologique, pour apprécier l'audace, ou le sens de la provocation de Stasiuk. Les préventions contre la composante orientale de cette partie de l'Europe sont très répandues ${ }^{17}$. Même si le voyageur note que les Albanais écoutent de la "techno-turque» (p. I52), il faut garder à l'esprit que leur grand héros national, Skanderberg, chrétien converti à l'islam, est celui qui a résisté aux Ottomans (p. 152). Cependant les mêmes Albanais se sentent exclus de l'Europe chrétienne et répondent par un contre-rejet. Alors que Stasiuk vient d'évoquer avec son ami Astrit le sort des travailleurs émigrés de l'Est en Europe de l'Ouest, ce dernier lui dit : «Ce n'est pas la même chose. Tu ne sais pas ce que signifie être Albanais en Europe.» (p. 155-156) Logiquement, certains de ses accompagnateurs, après avoir abusé du raki, scandent : «Ben Laden! Ben Laden! Ben Laden!» (p. I5I) Il faut aussi imaginer la réaction de certains lecteurs polonais, qui n'ont certes pas envie d'être confondus, au sein de l'ancien bloc de l'Est, avec l'Europe ottomane. Pendant longtemps, en effet, la Pologne s'est définie comme le bouclier de l'Occident chrétien, face aux Tatars, puis aux Turcs. Le cas le plus complexe reste celui de la Moldavie. Tout indique que l'on a affaire à un pays aliéné - minorités et majorité confondues - par une russification ancienne et massive. Stasiuk ne prend pas parti explicitement, ne désigne même pas les camps qui s'affrontent (séparatistes, moldovanistes et roumanistes ${ }^{18}$ ). Il rencontre des personnes de toutes les communautés, y compris tsigane. Il en ressort que les Transnistriens n'ont aucune histoire commune avec la Moldavie jusqu'en 1945, tandis que les Gagaouzes ont pâti, comme les Moldaves, de la Russie tsariste, depuis I8I2. Est-ce à dire qu'il légitimerait une sécession transnistrienne et pas celle des Gagaouzes, qui d'ailleurs, à l'inverse des Transnistriens,

17. Voir à ce sujet sa dernière pièce, non traduite en français, Czekając na Turka (En attendant un Turc), Wołowiec, Czarne, 2009.

18. J. Heurtaux et C. Pellen (dir.), I989 à L'Est de l'Europe. Une mémoire controversée, éd. de L'Aube, 2009, "Moldavie. Une indépendance qui divise (I99I)», p. IO3-I23. 
ont accepté une solution de compromis depuis 1995? Outre que ce n'est pas le terrain sur lequel veut se situer l'écrivain, le chapitre est structuré par une symétrie remarquable entre l'hospitalité gagaouze et celle d'Ukrainiens russifiés. Malgré le nationalisme des uns et des autres, ils sont unis, aux yeux du voyageur et de son lecteur, par un art de vivre commun : leur vie s'organise autour du jardin et de l'hospitalitér ${ }^{19}$ : «On entrait dans une petite cour couverte d'une vigne grimpante. [...] Elle [Elena] voulait tout nous montrer tout de suite. Nous allâmes dans le jardin.» (p. I69) Chez la Gagaouze, le «tout» se ramène au jardin. Chez Micha, Ukrainien russifié, c'est le jardin et la cave, bourrée de conserves de fruits et de légumes autant que de vin : "C'était un Eden moldave : jardin, festin et vœux au milieu des amis et de la famille.» (p. 187) La véritable identité, non pas celle décrétée par les frontières, ni même par la langue ou la religion, mais par l'art de vivre, permet d'imaginer une cohabitation. L'Orient serait ici le dénominateur commun de ces communautés.

Il ressort de cette dernière analyse que la référence à l'Empire ottoman fonctionne comme celle à Empire austro-hongrois : elle ne renvoie pas à une analogie historique mais à la positivité de certaines de ses valeurs. L'Europe de Stasiuk a, notamment, une vocation contemplative - gens assis devant leur porte (p. 250), femmes "mains sur leur giron" (p. I65, I70, 212). Mais, bien sûr, la date de publication du livre - 2004 - entre aussi en résonance avec l'actualité politique européenne : elle souligne l'altérité des régions qui accèdent à l'intégration européenne, cette année-là, et leur parenté avec la Turquie dont l'éventuelle intégration soulève tant de discussions. Il ne faut pas pour autant voir ici une prise de position de l'auteur. Il s'agit plutôt du résultat de sa démarche, à la fois phénoménologique et anthropologique. Les références au passé ne lui inspirent pas une pensée analogique de l'Histoire, elles accompagnent un mouvement de réappropriation de la mémoire et de l'identité.

En définitive, dans le maniement des analogies, Kapuściński se retrouve ici à contre-emploi, tandis que c'est Stasiuk qui semble recueillir son héritage et appliquer ce que son aîné a préconisé et pratiqué dans le reste de son œuvre. Ainsi, l'idée que les Polonais, et plus largement les Centre-Européens, peuvent se sentir proches des Africains, parce que non seulement ils n'ont jamais possédé de colonies, mais qu'ils ont été eux-mêmes «colonisés» à plusieurs

19. La civilisation du jardin et l'hospitalité sont des motifs que l'on retrouve chez deux autres voyageurs occidentaux reçus par des minorités turques d'Europe (P. Leigh Fermor, Le Temps des offrandes, t. I, et Entre les fleuves, t. II, [1986], trad. de l'anglais par G. Villeneuve, [1992], Payot \& Rivages, 2003, p. 315 et suiv.); N. Bouvier, L'Usage du monde [1963], Payot \& Rivages, 200I, p. 74. 
reprises $^{20}$, sous-tend déjà, d'après George Gasyna ${ }^{21}$, le dernier récit du recueil Bush à la polonaise. Il faut rendre justice à Kapuściński dont les grands livres sur le tiers-monde témoignent d'un bel effort de décentrement et de compréhension de l'altérité, qu'il a revendiqué jusqu'au bout. «Bien plus tard, écrit George Gasyna, dans le second volume de Lapidarium, Kapuściński se décrirait comme un "chercheur d'Altérité", recherchant les moyens de construire l'altérité comme une valeur positive ${ }^{22}$.» (Ibid., p. 6I) S'il reste une différence irréductible entre nos deux auteurs, c'est que Ryszard Kapuściński postule une innocence historique des Polonais, exempts de passé colonial, tandis que Stasiuk compare, malgré eux, des Blancs (centre-européens, et pas uniquement polonais), volontiers racistes, aux Noirs qu'ils méprisent. D'autre part, ce n'est pas la même démarche de valoriser l'Altérité et de découvrir l'Altérité qui est en nous. Il faut dire aussi que l'Autre n'est plus l'ancien colonisé du tiers-monde, mais le citoyen soviétique, tantôt colon, tantôt colonisé, pour ce qui est d'Imperium, et les peuples voisins, pour ce qui est de Sur la route de Babadag.

\section{Des positions à fronts renversés?}

\section{Entre Orient et Occident, un point de vue polonais?}

L'analyse politique confirme-t-elle que les positions ne sont pas figées, pas toujours conformes aux réputations, et que sous certains angles, l'ancien reporter communiste et l'ancien détenu des prisons communistes peuvent sembler écrire «à fronts renversés»?

Alors que tous deux sont profondément anti-nationalistes, on est surpris de trouver le grand reporter plus ethnocentré que l'écrivain qui vit retiré dans la Pologne profonde ${ }^{23}$. Kapuściński multiplie en effet les références à la culture et l'histoire polonaises. Cela se comprend aisément quand il voyage dans les Kresy, les «territoires perdus» (p. 282, 293). Quand il cherche un équivalent

20. A. Domosławski, Kapuściński..., ouvr. cité, p. I46, 219.

2I. G. Gasyna, art. cité, p. 69.

22. "Much later, in the second volume of Lapidarium, Kapuścinski would describe himself as a researcher of Otherness, seeking out modes of constructing alterity as a "positive value [...]». (Je traduis)

23. Sur ce point, M. Horodecka ("Travel Book As A Form Of Intercultural Dialogue : Imperium By Ryszard, Kapuściński», dans Metamorphoses of Travel Writing : Across Theories, Genres, Centuries and Literary Tradition», G. Moroz et J. Sztachelska [éd.], New Castle upon Tyne, Cambridge Scholars Publishing, 20IO, p. 197-207) tente une réponse aux critiques de M. Waldstein ("Observing Imperium : A Postcolonial Reading Of Ryszard Kapuściński’s Account of Russia», Social Identities, n ${ }^{\circ}$, vol. 8, 2002, p. 48I-499). 
polonais à la destruction de la cathédrale du Christ Sauveur de Moscou par Staline (p. I08), l'analogie a manifestement une fonction pédagogique. Mais le raccourci n'est-il que la recherche d'un effet brillant? C'est le même Molotov qui fut chargé de cette destruction et qui signa le pacte «devant effacer la Pologne de la surface de la terre» (p. II6). Que penser de l'insistance sur le thème de la restitution des églises, qui ramène forcément celui de leur confiscation (p. 99, I04-II6, I37, I82-184)? Il s'agit d'une réalité objective et hautement symbolique, mais peut-être aussi d'un choix quelque peu paradoxal, de la part d'un intellectuel que son biographe présente comme peu ou pas religieux ${ }^{24}$. Il faut peut-être distinguer parmi ces thèmes propres à séduire un lectorat polonais deux catégories : ceux qui sont l'objet d'une lecture politique clairement engagée - c'est ainsi que Kapuściński salue la proclamation d'indépendance de l'Ukraine, en écrivant que «l'Europe vient de s'agrandir d'un grand État» (p. 29I) et ceux qui présentent davantage de plasticité. En Abkhazie, à Novogorod ou Kichinev, le renouveau religieux est présenté comme une poignante sortie des catacombes (p. 137). À Irkoutsk, le prêche des vieux-croyants réveille la hantise du fondamentalisme. À l'opposé, Stasiuk semble très détaché de son identité nationale, traitant par la satire les touristes polonais qu'il croise (p. 50, 9I), reconnaissant la figure de Souvorov sur les billets moldaves sans évoquer son rôle dans la répression des soulèvements polonais en I768 et I794 (p. I84). La seule exception intervient cependant en Moldavie, lorsque son hôte évoque les «bons souvenirs" que lui a laissés un voyage à Varsovie avec son groupe folklorique. Le narrateur prend ses distances en qualifiant la période de «lugubres années quatre-vingt» (p. I86). Quant à la vie religieuse des contrées qu'il parcourt, elle est singulièrement discrète et non catholique. On s'attendrait à l'évocation d'une Europe orthodoxe. Or ce sont les traces mélancoliques laissées par l'islam et le judaïsme qui s'imposent ainsi qu'un phénomène récent : les conversions à l'évangélisme, un protestantisme d'importation, américain (p. I7I-172, 195). Ce parti pris surprend quelque peu de la part de Stasiuk qui se montre souvent sensible à la dimension religieuse de la vie, dans son œuvre ${ }^{25}$, et assume une identité culturelle catholique. Mais sa position est toujours celle d'une «tendresse ironique ${ }^{26}$, selon laquelle le sentiment d'appartenance n'interdit aucune pensée critique ${ }^{27}$.

24. A. Domosławski, Kapuścinski..., ouvr. cité, p. 354.

25. Voir en particulier les nouvelles I, II et XV de Contes de Galicie, ouvr. cité.

26. D. Kozicka, «Podróże Dysia Marzyciela», Dekady Literackie, nº 6, 2005, p. 2I4. Cette critique dépeint A. Stasiuk comme un «czuly observator» (« un observateur tendre»).

27. Voir ses pages consacrées au pape Jean-Paul II Dukla: (Wołowiec, Czarne, 1997), trad. du polonais par A. Żuk et L. Alaux, Bourgois, 2003, p. I4I et suiv.; Fado, ouvr. cité, p. I45-I58.) ainsi que son article «Païenne Pologne» paru dans Le Monde diplomatique, octobre 20IO, p. I5. 
Par-delà le rapport à leur identité nationale, c'est peut-être leur distance à l'égard de l'Occident qu'il est intéressant de mesurer. Sous cet angle, leurs lectures respectives sont peut-être révélatrices. La culture de Kapuściński semble bipolaire, partagée entre références occidentales (p. 99, 130, 136, et passim) et lectures impressionnantes de la littérature mais aussi des sciences humaines russes (p. 96, I00, I02, et passim). La littérature d'Europe centrale n'est représentée que par des auteurs polonais (p. 136, 280, 300) et ukrainiens (p. 289-292). Dans le texte de Stasiuk, c'est à peu près l'inverse. Si l'on se reporte aux notes en fin de volume, on reconnaît des noms d'écrivains roumains, slovènes, albanais, ex-yougoslaves, hongrois. Pas une référence russe, ni occidentale, pas même Sur la route de Jack Kerouac, qui est le modèle sous-jacent des errances en auto-stop du premier chapitre. Il est tentant de ne voir ici qu'une sélection appropriée au sujet du livre. Mais si l'on tente de reconstituer les lectures de Stasiuk d'après ses œuvres, il semble avoir lu la littérature occidentale dans sa jeunesse ${ }^{28}$, à une époque où elle était difficile d'accès et mal vue du pouvoir, et s'en être détourné au profit des littératures d'Europe du Sud-Est, dans sa maturité, après 1989, et surtout à partir de 1996, année où il a fondé avec sa femme les éditions Czarne ${ }^{29}$, consacrées précisément à ces littératures méconnues de "petits» pays, écrites dans les langues dites «rares». On peut se demander si les lectures de l'écrivain éditeur ne vont pas de pair avec une attitude de résistance à l'occidentalisation qui accompagne la Transition.

Sur ce terrain, Kapuściński semble de nouveau à contre-emploi. Non seulement il approuve la fin du communisme (p. 93) et de l'empire (p. II9), mais il présente l'Occident comme source de valeur ayant manqué aux Caucasiens :

Tout contact avec la pensée libérale et démocratique de l'Ouest était impossible, et comme les voisins ne fournissaient pas d'exemple, il n'y avait pas de leçon à apprendre de qui que ce soit. (p. 132)

L'exemple d'attaque anti-occidentale qu'il produit - celle du prêtre d'Irkoutsk - vient de l'extrême-droite nationaliste. (p. I84-190) À l'inverse, le libertaire Stasiuk n'est pas dupe de la nouvelle liberté de circuler, qui ne «vaut rien" aux yeux du paysan roumain avec qui il discute, faisant du voyageur la "manifestation flagrante de l'inégalité» (p. 28). Sur la place de Sarandë (Albanie), jonchée de détritus, le voyageur note que le vent, venant de l'ouest "au sens propre et figuré», n’a rien «apporté qui ait eu une quelconque valeur»

28. A. Stasiuk, Jak zostałem pisarzem (próba autobiografii intelektualnej) (Comment je suis devenu écrivain [essai d'autobiographie intellectuelle]) [1998], rééd. Wołowiec, 2008, non traduit. 29. Maison d'édition aujourd'hui basée dans le hameau de Wołowiec. 
(p. I46). Plus important, sur le plan de la composition, le motif du monde disparaissant, est lié, dans sa première occurrence, à l'avenir de consommation que promet la Transition :

Tout ceci disparaitra, $[\ldots]$ ce seront des versions du quotidien de plus en plus abâtardies, qui se feront passer pour une fête, de la misère déguisée en richesse, la crasse des réjouissances, la multiplication des ordures, le plastique qui s’abîme sur-le-champ mais qui, comme déchet et décharge, dure presque éternellement. (p. 19)

Condamnation esthétique, écologique et spirituelle. Pour autant, l'Occident n'est pas diabolisé par une pensée manichéenne, comme l'indique une parole éclairante du chœur, dans la pièce de 2005 :

Ils vont chercher des diamants à l'Ouest, parce que l'Ouest n'a rien d'autre à leur offrir. Ils vont chercher des voitures parce que l'Est n'a rien d'autre à demander à l'Ouest. (p. 8)

Logiquement, si Kapuściński se montre, dans ce livre, plus occidentalocentré que son compatriote, il porte un regard plus distant sur l'Orient. À première vue, il s'en tient pourtant à des données objectives : asiatisation de l'empire sur le plan démographique, avec l'émigration des minorités allemandes et de nombreux Russes (p. I2I, 336), et sur le plan linguistique. Le turc est déjà la deuxième langue de l'empire, et il décrit un processus de dérussification, qui remonte sans doute à la perestroïka, si l'on en juge par sa difficulté à trouver des enfants russophones, par exemple en Bachkirie (p. 177) ou chez les Karakalpaks (p. 278). Ce phénomène se traduit dans le débat politique entre les partisans du droit du sol et les défenseurs du droit du sang, comme Soljenitsyne (p. 292). Kapuściński ne semble pas prendre parti, probablement tiraillé entre son anti-impérialisme et une distance subjective avec l'Orient soviétique. Il souligne l'altérité d'une population caractérisée à ses yeux par son caractère imprévisible (p. 132, 150) et porte un regard négatif sur l'asiatisme russe, puis soviétique : c'est le despotisme de Moscou «imprégnée d'influences mongoles", opposée à Novgorod, la cité démocratique (p. 306-307), c'est «le faste oriental des Brejnéviens" à Bakou (p. I47).

Un exemple est particulièrement révélateur de la différence de regard entre nos deux auteurs. Kapuściński raconte qu'il a passé quatre jours à l'aéroport d'Iakoutsk, bloqué par les intempéries et compare les Sibériens qui l'entourent aux habitants des pays du tiers-monde :

Partout le même spectacle : des gens assis, figés, des heures entières sur de vieilles chaises, [...]. Des hommes abattus et moroses, en état de somnolence quasi chronique, désœuvrés, sans but, inutiles et plongés (du moins apparemment) dans une torpeur intellectuelle [...] (p. 204) 
RysZard KapuściŃski et ANDrZej STASIUK, DEUX ÉCRIVAINS POLONAIS À Fronts RENVERSÉS?

À l'opposé, Stasiuk se réjouit de la persistance d'une humanité contemplative:

[...] je me prends à imaginer que c'est quelque part par ici [à Konieczna], [...] que commence ce méridien qui finit par se perdre dans la mer Ionienne,

[...] le long duquel, tels des oiseaux sur un fil de fer, des types, pareils à ceux

d'ici, restent assis. [...] ils manquent toujours d'argent et sont donc obligés de se déplacer, de pratiquer l'esquive pour berner la réalité, et le soir s'y retrouver quand même. (p. 250)

Dans cet exemple presque caricatural, Kapuściński fait une lecture politique et passablement occidentalo-centrée, tandis que Stasiuk a une approche à la fois anthropologique et métaphysique, en tout cas complice et empathique.

La distance que chacun adopte par rapport à l'Orient et à l'Occident détermine le rôle qu'ils se donnent. Kapuściński se présente en médiateur, pédagogue initié à l'altérité des Russes, des orientaux, et indispensable interprète auprès de son lectorat occidental :

Tout départ en avion est subordonné au pot-de-vin donné à l'une des mafias dont précisément deux leaders se tiennent devant moi. C'est dans ce type de situations que se perdent les Occidentaux [...] (p. 245)

Au passage, on se demande pour qui écrit Kapuściński : s'adresse-t-il aux Polonais, qu'il constitue alors comme un public occidental incapable de comprendre sans son aide l'URSS, ou bien s'adresse-t-il par-dessus leur tête aux Occidentaux? Est-ce son expérience du tiers-monde ou sa "polonité» qui lui permet de maîtriser les codes des deux mondes? La posture de Stasiuk est aux antipodes. Il n'est pas un intermédiaire, il se fond avec son objet, sans doute parce qu'il se définit davantage comme un citoyen des Carpates ou Galicien que comme Polonais. Stasiuk n'hésite pas à endosser le "nous» quand il faut assumer un élément réputé honteux de l'identité de l'Est, avec un mélange d'humilité - «Nous sommes tous des orphelins d'un empereur ou d'un dictateur." (p. 27) -, d'autodérision et de goût de la provocation : «Oui, je me sentais comme un barbare venant de cet est, toujours bordélique et inachevé.» (p. I26)

Au bout du compte, Kapuściński est animé par un désir de changement, désir que le tiers-monde sorte de son sous-développement, quitte à perdre son «objet»: pas seulement au sens de domaine professionnel, mais aussi au sens affectif. Il ne laisse filtrer qu'une seule fois son attachement paradoxal pour la "déglingue», à Erevan : «Immédiatement j'ai le sentiment de me trouver dans mon (cher) tiers-monde [...]» (p. 242). À l'opposé, tout le dernier chapitre de Sur la route de Babadag dévoile ce que les voyages ont appris à Stasiuk sur lui-même, son "amour pour le délabrement» (p. 247), un "amour désespéré» (p. 285) : «Soit. Je ne peux cacher que je suis attiré par la disparition, la désagrégation [...].» (p. 282) 


\section{Regards sur le communisme et la Révolution}

Aurions-nous à faire à un tiers-mondiste ethnocentré et à un citoyen du monde conservateur, qui ne «souhaite pas de changements» (p. 252)? La pierre de touche que constitue la relation au communisme donne une impression de chassé-croisé, mais celle-ci résiste-t-elle à l'analyse? Kapuściński développe une critique anti-stalinienne obsédante, tandis que les attaques anti-communistes dans Sur la route de Babadag, sont plus discrètes et visent, paradoxalement, les dictatures périphériques et souvent hétérodoxes de l'ancien bloc. L'antistalinisme s'articule autour de quatre thèmes récurrents : le recrutement du NKVD parmi des orphelins délinquants (p. I49, 209), la grande famine des années 1930 en Ukraine (p. 109, II3, 2II, 288, 293), le souvenir des camps et l'interdiction de poser des questions, expérimentée dans son enfance. Alors que Kapuściński revient sur les massacres de Katyń et de Vinnitsa (p. 282), dont les victimes étaient polonaises et ukrainiennes, Stasiuk opère un décentrement, en se rappelant tour à tour les dictatures de Ceauşcescu (p. 24, 27, 342-345), Hodja et Tito :

$\mathrm{Au}$ fond des vallées, dix mille corps reposaient. Je traversais le plus grand cimetière anonyme de Slovénie. L'été I945, les communistes de Tito avaient assassiné à cet endroit, sans jugement et sans témoins, des prisonniers remis pas les Alliés. C'étaient des partisans qui avaient combattu du mauvais côté. (p. I29)

La dictature d'Enver Hodja, en Albanie, lui inspire moins une analyse historique ou politique qu'une poétique de la laideur et de la paranoïa : «Des crânes gris en béton sortaient de terre à hauteur d'un mètre et regardaient de leurs noires fentes horizontales.» (p. 136) Il s'agit des soixante mille blockhaus construits pour se défendre des innombrables ennemis désignés par le dictateur : «Les crapauds gris en béton se dressaient tantôt solitaires, tantôt par trois ou quatre, ils surveillaient [...].» (p. I4I)

On peut invoquer la différence d'objet historique et géographique pour expliquer le point de vue polono-centré de Kapuściński et décentré chez Stasiuk. Mais c'est aussi l'essence même de la dictature qui est interrogée différemment. La thèse de Kapuściński consiste à lire le communisme soviétique comme le prolongement de l'impérialisme russe, au point que l'on peut se demander si cela ne sauve pas, paradoxalement, l'idée communiste, comme jamais véritablement expérimentée, toujours dévoyée. Stasiuk repère une folie politique qui s'est développée là où l'on s'est réclamé d'une indépendance par rapport à la tutelle soviétique, voire du non-alignement.

L'échec du communisme réel interdit-il toute pensée révolutionnaire à nos deux écrivains voyageurs? Bien que Kapuściński rencontre surtout des cadres de la société - professeurs, poètes, responsables politiques de niveau 
local - lorsqu'il va au-devant des ouvriers, ce sont souvent des figures du peuple en lutte : fin de grève des mineurs à Vorkouta (p. I6I), grève des mineurs et des étudiants en Ukraine (p. 288). Stasiuk raconte des rencontres très différentes : il s'agit toujours d'individus, ruraux, et pas du tout combatifs, parfois "ostalgiques» (p. 27, I88). Est-ce à dire que pour Kapuściński la Transition est une période révolutionnaire et que la question laisse son cadet indifférent? À vrai dire, celui-là hésite entre plusieurs lectures de l'événement. Il rappelle que le processus de décomposition était "amorcé bien avant", dans un système qui dysfonctionnait depuis longtemps (p. IOO, 284, 323), ce qui renforce l'hypothèse d'une fin d'empire. Pourtant, il qualifie aussi ce phénomène de "révolution sociale» (p. 33I), pour tempérer rapidement en soulignant ses limites : il s'agit d'une révolution "par le haut" (p. 96, 33I), d'une "révolution de velours, inachevée» (p. 332). Kapuściński reproche à cette révolution, au moment où il écrit, de se limiter au politique, sans la traduction sociale que serait une amélioration de la vie quotidienne. Il craint une nouvelle dictature (p. 332) autant qu'un capitalisme sauvage (p. 337). On pourrait résumer en disant que Kapuściński exprime un désir de révolution frustré. De son côté, bien qu'il n’y fasse aucune allusion, Stasiuk est fils d'ouvrier, autodidacte, et ses notices biographiques lui prêtent une sensibilité anarchisante. Sans qu'il y ait la moindre revendication de sa part, on remarque que son livre est encadré par deux images du monde ouvrier : celui de sa jeunesse, lorsqu'il effectuait des trajets sans but, dans les trains de banlieue (p. 19) et celle des ouvriers d'une aciérie, "tragiques comme le crépuscule du prolétariat» (p. 359), dans le Krompachy d'aujourd'hui. Mais si sa sensibilité sociale ne trahit pas ses origines, elle opère tout de même un déplacement, de la ville vers la campagne. C'est ainsi qu'il tente d'effectuer, à quelques mois d'intervalle, deux pèlerinages sur la tombe de "rois paysans", meneurs de révoltes, cinq siècles plus tôt : George Doja a fini démembré, sur ordre des seigneurs hongrois, tandis que Jakub Szela est tombé sous les coups des Autrichiens (p. 62-63). L'impossibilité de retrouver la tombe de ces héros oubliés lui inspire un commentaire pessimiste : "Jamais, nulle part, il ne reste rien des rébellions des miséreux.» (p. 63) Ces pages sont l'un des rares moments où il est tenté par un positionnement politique : "Des pensées de gauche s'emparaient de moi, alors même que j'étais absolument dépourvu d'enthousiasme révolutionnaire.» (p. 68) Mais ce n'est pas son registre, et lorsqu'il formule une définition du capitalisme, c'est pour démystifier la "nouvelle religion», en maniant la paraphrase biblique : "Il ne te reste que le distributeur de billets de Suceava, seule émanation de ce mal lointain et omnipotent qui empêche à jamais les derniers de devenir les premiers." (p. 68) Stasiuk assume ses contradictions : une sensibilité sociale, mais un 
désir de permanence, et non de changement, sans doute parce que, dans cette région du monde, la première est synonyme de paix et le second de violence (p. 252). Non dénué d'auto-ironie, il s'accuse de nourrir des "pensées réactionnaires", lorsqu'il fait le projet de créer des «réserves», bien conscient que les intéressés «lui botteraient le cul tout simplement» (p. 259).

Kapuściński est pris dans une autre contradiction. Il a parfaitement conscience que les mouvements de révolte et de sécession contre l'empire sont des «révolutions nationalistes» (p. I77). Or, pour lui, il y a trois fléaux : le nationalisme, le racisme et le fondamentalisme religieux (p. 258). Cela fait qu'il est tiraillé entre son anti-impérialisme et son anti-nationalisme. Du coup, lui qui a toujours défendu, face à la tradition anglo-saxonne de l'objectivité, la tradition continentale du journalisme engagé ${ }^{30}$, se trouve parfois paralysé. C'est ainsi qu'après avoir amplement donné la parole aux Arméniens d'Erevan et de Stepanakert, il renvoie dos à dos les belligérants. (p. 259) À l'inverse, malgré son désir d'écouter chacun, sans parti pris, y compris dans un pays où les conflits continuent de couver, comme la Moldavie, Stasiuk s'engage, sans un mot, à la "frontière" transnistrienne. L'hostilité du garde rappelle l'époque de la guerre froide. La scène est pleine de suspense.

Ils avaient immédiatement remarqué la caméra et la peur immémoriale de ceux qui ont quelque chose à cacher se réveilla en eux. Ils dirent que nous avions filmé le passage. Évidemment que nous l'avions fait, mais nous affirmâmes le contraire. (p. I80)

Sans s'être concertés, les voyageurs résistent : ils ont filmé la zone interdite, ils mentent à leurs interlocuteurs, l'un des compagnons de Stasiuk parvient à remplacer subrepticement la cassette litigieuse par une vierge, et ils paient un pot-de-vin pour conserver leur caméra. Mais un tel épisode héroïque est un hapax, précédé d'un aveu qui ne cherche pas à en imposer : "Nous avions un peu peur d'y aller.» (p. I78)

\section{Échapper au politique?}

Pour des raisons en partie différentes, nos deux auteurs portent, au final, un regard critique sur l'effondrement de l'empire et la Transition qui l'a suivi, alors même qu'ils ne sont pas nostalgiques de l'ancien système. Tous deux évoquent un désir d'échapper au politique, dans lequel on peut reconnaitre un héritage de la dissidence. Des penseurs comme Václav Havel, ou György

30. R. Kapuściński, Lapidarium III, Varsovie, Czytelnik, I997, non traduit sauf p. 7I-86, trad. du polonais par C. Potocki, Communications, $\mathrm{n}^{\circ}$ 79, 2006, Des faits et des gestes. Le parti pris du document, 2, p. 305-317, 309-310, 313. 
Konrád ${ }^{31}$, auquel se réfère Stasiuk, ont étayé l'idée que refuser la politisation dans tous les domaines, qu'imposait la doctrine communiste, était en soi une forme de résistance. Mais ce thème anti-totalitaire devient sous la plume de Kapuściński une critique contre la saturation (p. 284) qui accompagne l'effondrement de l'empire, et une optique de reportage difficile à respecter.

La langue de la politique omniprésente a chassé des médias, et pis encore, de notre mémoire, les mots permettant de parler des problèmes privés, de drames personnels, de souffrances particulières [...]. Mais comment faire autrement? Lampleur des événements en cours ne peut être abordée qu’avec une langue et des concepts généraux, synthétiques, abstraits. (p. 318)

À quelques reprises, Kapuściński explore en vain le rapport à la nature comme échappatoire : les poètes de Bachkirie lui expliquent que même la poésie de la nature est une forme de résistance face à la tentative de destruction de leur langue (p. 179). Il retire de la littérature des camps l'idée que la «nature fraternise avec le bourreau» (p. 218). Enfin celle-ci est complice de l'effacement de l'Histoire :

La moitié de l'archipel du Goulag a déjà sombré dans les marais et la boue. La moitié des camps de Sibérie a été envahie par la forêt [...]. Dans quelques années, les dernières traces de l'univers des camps auront été effacées. (p. 22I-222)

Kapuściński est un poète politique. Stasiuk, qu'une véritable horreur de l'Histoire habite, que révoltent "la lueur menaçante de la géographie politique et l'éclairage mort de la géographie économique", adopte à peu près la démarche inverse. Il s'en remet plus volontiers au temps circulaire de la nature qu'aux dates du temps linéaire de l'Histoire, ses voyages portent la marque des saisons, et son livre l'empreinte de son rythme de vie, transhumant : toutes les scènes d'écriture, dans son œuvre, ont lieu à la mauvaise saison, ses déplacements, de préférence quand les routes sont dégagées. Aussi n'est-ce pas un hasard si le final de son livre est rythmé par le motif du dégel (p. 359-360), dont il fait l'emblème de son Europe :

Le mois de mars touche à sa fin et j'entends la neige qui, dans l'obscurité, descend de la montagne. [...] ceci est le véritable visage de mon coin de terre, de mon continent, ce changement qui ne change rien, ce mouvement qui s'épuise de lui-même. (p. 283)

Quand on sait quels espoirs a soulevés ce que l'on a appelé par métaphore «le dégel » en 1956, le retour à la signification littérale du terme est peut-être ici plus qu'une simple notation descriptive : un choix hautement symbolique.

Malgré des cadres spatio-temporels et des partis pris assez différents, quelques convergences idéologiques se dessinent : un regard critique sur le

3I. Y. Andrukhovych, A. Stasiuk, Mon Europe, ouvr. cité, p. Ioo. 
communisme ainsi que sur le nouveau monde issu de l'effondrement de l'URSS. Mais Kapuściński et Stasiuk sont assurément moins unis par une commune identité polonaise que par leur distance avec celle-ci, au moins sur un point : tous deux sont anti-nationalistes. L'anti-impérialisme pourrait aussi les réunir, mais une nuance les distingue. Dans le récit de son premier séjour dans le Caucase, en 1967, Kapuściński défend l'idée que tous les peuples «ont connu une période d'extension, d'élargissement, ou du moins de défoulement patriotique", qui leur permet, lorsque leurs territoires se sont réduits, de " compenser leurs instincts expansionistes par une sensation de profondeur» et de préserver ainsi «un certain équilibre psychique» (p. 66). Formulée au sujet du Caucase, cette hypothèse ressemble davantage à un plaidoyer pro domo de l'ex-Grande Pologne qu'à une psychologie des peuples scientifiquement fondée. En revanche, Stasiuk est partisan d'un anti-impérialisme intégral :

L'existence des petits pays au tempérament modéré est tout bonnement un défi lancé aux idées dominantes sur l'expansion, la puissance, la grandeur, le sens et tous les autres clichés. Quant à moi, j'ai toujours voulu vivre dans un petit pays et jamais, Dieu m'en garde, dans un plus grand. (p. I30-I3I)

Kapuściński et Stasiuk s'opposent davantage par la méthode et la forme. En digne héritier de ses parents instituteurs, le premier croit au savoir et à la raison, s'emploie à conférer la plus haute teneur documentaire et la plus grande clarté pédagogique possibles à son texte. Si son livre est assez différent de ses autres œuvres, c'est sans doute moins, comme le suggère son biographe, parce qu'il se serait transitoirement renié, pour se dédouaner de son passé communiste, avant de revenir à ses idéaux de jeunesse ${ }^{32}$, que parce qu'il avait coutume de postuler un sens, d'interpréter les événements et que cette fois-ci, malgré le recours à des grilles de lecture éprouvées, le sens se dérobait :

Ce livre est polyphonique. [...] Toutefois, contrairement au principe polyphonique, l'ensemble n'aboutit pas à une synthèse claire et nette, mais se désintègre et se disloque pour la bonne raison que son principal sujet, son thème central - la grande puissance soviétique - s’est lui-même désagrégé pendant que j'écrivais ce livre. (p. 9)

Pour le dire autrement, la situation renforce les contradictions qui sont, de toute façon, au fondement de la démarche du reporter qui a cherché, me semble-t-il, à combiner objectivité et engagement. À l'inverse, Stasiuk semble conjuguer subjectivité et non-engagement. Ou, plus exactement, il déploie son engagement essentiellement dans la forme, par un usage performatif de la comparaison ou une esthétique de la laideur, notamment. À travers une

32. A. Domosławski, Kapuściński..., ouvr. cité, p. 287, 429-44I, 447. 




écriture très travaillée dans les deux cas, des tempéraments se différencient : à Kapuściński, le sens du tragique et le comique aux dépens d'autrui, à Stasiuk la mélancolie et l'humour y compris appliqué à soi-même. Toujours est-il que ces deux textes inversent magistralement la tendance dégagée par Andrzej Stasiuk dans son essai Mon Europe :

On partait pour une guerre étrangère, on se sauvait devant les armées, on fuyait la misère et la faim.

Voilà pourquoi l'Europe centrale n'a jamais eu ses grands voyageurs. [...] Partir par curiosité? Pareille pensée ne peut venir à l'esprit que si nous sommes persuadés que rien n'arrivera à notre maison [...]. (p. I09) 